\title{
Autômatos celulares probabilísticos aplicados à modelagem da propagação de incêndios de vegetação
}

\author{
Rodolfo Maduro Almeida \\ Instituto de Engenharia e Geociências, Universidade Federal do Oeste do Pará \\ E-mail: rodolfo.almeida@ufopa.edu.br \\ Helena França \\ Centro de Engenharia, Modelagem e Ciências Sociais Aplicadas, Universidade Federal do ABC \\ E-mail: helena.franca@ufabc.edu.br
}

\author{
Elbert Einstein Nehrer Macau, Fernando Manuel Ramos \\ Laboratório Associado de Computação e Matemática Aplicada, Instituto Nacional de Pesquisas Espaciais \\ E-mail: elbert@lac.inpe.br, fernando@lac.inpe.br
}

\begin{abstract}
Resumo: Este trabalho apresenta uma metodologia para modelagem e simulação de incêndios de vegetação utilizando a abordagem baseada em autômatos celulares probabilísticos. O formalismo de modelagem utilizado possibilita estabelecer uma relação explícita dos parâmetros do modelo com dados meteorológicos e espaciais obtidos por sistemas de informações geográficas. O contexto de aplicação do modelo é o Parque Nacional das Emas, situado no extremo Sudoeste do Estado de Goiás. Um amplo acervo de dados espaciais que inclui o inventário histórico de incêndios mapeados, mapa de vegetação, modelo digital de elevação, malha de drenagem, malha de aceiros; somados a dados meteorológicos obtidos por estações de coleta situadas no entorno do Parque, deram subsídios para a compreensão e a modelagem do comportamento do fogo nesta Unidade de Conservação. A metodologia de ajuste desenvolvida mostra a boa capacidade de o modelo ser ajustado para simular incêndios reais, com certo nível de precisão em termos de extensão do incêndio e tempo de duração.
\end{abstract}

\section{Introdução}

Um incêndio de vegetação ocorre com a presença indesejada do fogo, que se propaga descontroladamente sobre a superfície, consumindo a vegetação. Independente das causas de um incêndio de vegetação, que pode ser tanto antropogênica (acidental, intencional ou negligente) quanto natural (causada por raios), os incêndios de vegetação são considerados catástrofes naturais, não só pelos danos ambientais, mas também pelos danos econômicos e humanos, podendo destruir bens materiais, e por em risco a vida das pessoas [8]. Neste sentido, surge a importância em se estudar a dinâmica de propagação de incêndios de vegetação, onde se destaca a área da modelagem da propagação do fogo em incêndios de vegetação, que é uma área intrinsicamente experimental, que surgiu da necessidade do homem compreender, e consequentemente, desenvolver mecanismos para prever e controlar este fenômeno.

Um modelo de propagação do fogo é uma ferramenta que possibilita simular cenários de propagação de um incêndio em função dos fatores que condicionam seu comportamento [7]. A integração destes modelos com dados oriundos de sistemas de informações geográficas tem propiciado um salto qualitativo no desenvolvimento de ferramentas computacionais que auxiliam na tomada de decisão em ações que envolvam o monitoramento, a prevenção e o combate a incêndios de vegetação [7]. O comportamento do fogo é conduzido pela interação de três conjuntos de fatores, que são: a vegetação, as condições atmosféricas e a topografia [8]. A vegetação fornece o combustível que alimenta as chamas e, em termos gerais, inclui os fatores: arranjo, forma, abundância, distribuição espacial e teor de umidade da vegetação. As condições atmosféricas influenciam tanto no teor de umidade da vegetação quanto na dinâmica de propagação do fogo, e pode ser descrita pelos fatores: temperatura do ar, umidade relativa do ar, velocidade do vento e direção do vento. A topografia descreve a forma do relevo e inclui os fatores declividade ${ }^{1}$ e orientação de vertentes ${ }^{2}$. Dentre os fatores

\footnotetext{
${ }^{1}$ A declividade é a inclinação da superfície do terreno em relação à horizontal, ou seja, a relação entre a diferença de altura entre dois pontos e a distância horizontal entre esses pontos.
} 
mencionados, os que mais influenciam na dinâmica de propagação do fogo, determinando a forma e a intensidade de propagação da frente de fogo, são a velocidade e a direção do vento, e a declividade e a orientação de vertentes. Tanto morro acima, quanto a favor do vento, o encurtamento da distância entre as chamas e a vegetação adiante da frente de fogo intensifica a transferência de calor, levando a vegetação à ignição mais rapidamente [8].

As abordagens utilizadas para modelar a propagação do fogo podem ser classificadas em dois grupos: aquelas baseadas na representação paisagem como um domínio espacial contínuo; e aquelas que representam a paisagem por um domínio espacial discreto, geralmente descrito por um reticulado bidimensional quadrado [7]. Embora sendo uma área consolidada há mais de cinco décadas, a compreensão do fenômeno de propagação do fogo em incêndios de vegetação ainda é incompleta, e as abordagens semi-empírica e empírica surgem como alternativa para descrever uma série de relações entre os processos fundamentais da combustão e transferência de calor e os fatores seus condicionantes [4]. Além disto, pela complexidade do fenômeno, onde muitos fatores se relacionam em diferentes escalas de espaço e de tempo, a estocasticidade vem sendo incluída nas componentes do modelo, visando representar flutuações significativas nos seus valores. Uma alternativa que vem sendo empregada é o uso de técnicas de ensemble, onde a estocasticidade é inserida nas condições atmosféricas, de maneira sistemática ao longo do tempo, gerando projeções probabilísticas de cenários de propagação de um incêndio [3]. Outra alternativa, que é a adotada neste trabalho, é o uso de modelos probabilísticos de propagação do fogo, onde a componente estocástica é introduzida implicitamente no comportamento do fogo, tanto espacialmente quanto temporalmente, em função dos fatores condicionantes [1,2].

Neste trabalho, um modelo empírico, probabilístico e domínio espacial discreto é proposto, parametrizado, ajustado e aplicado para simular a propagação de incêndios de vegetação. Nos modelos probabilísticos, a propagação do fogo é modelada como um evento estocástico, com uma probabilidade associada. Esta abordagem de modelagem é de natureza puramente empírica, e permite o desenvolvimento de um modelo de propagação que possua nível de confidencia com as características particulares da região de estudo onde ele foi ajustado e aplicado. Este artigo é organizado conforme descrito a seguir. Na Sessão 2 é apresentada uma breve descrição da região de estudo e os fatores que nela condicionam a propagação do fogo. Na Sessão 3 o modelo é discutido e apresentado, assim como as suas parametrizações e a metodologia de ajuste. Na Sessão 4 os resultados são apresentados. E por fim, na Sessão 5, são discutidas as considerações.

\section{2. Área de estudo}

Criado em 1961, o Parque Nacional das Emas (PNE) é a maior área preservada do Bioma Cerrado em todo o planeta, com uma área de um pouco mais de 132.000 hectares, está localizado no extremo sudoeste do Estado de Goiás, próximo às dividas com os Estados de Mato Grosso e Mato Grosso do Sul, conforme exibido na Figura 1(a). O clima da região do PNE é sazonal tropical, com o período de seca se estendendo de junho a agosto, e estação chuvosa se estendendo de outubro a abril. Durante o mês se setembro ocorre a transição da estação seca para a chuvosa, e no mês de maio ocorre a transição da estação chuvosa para a seca. O relevo do PNE é predominantemente plano, com grande parte de sua extensão situada no topo de uma chapada, onde as altitudes variam de 800 a 900 metros. A vegetação apresenta quase todas as variações fisionômicas do Bioma Cerrado, predominando as fisionomias abertas de vegetação, onde campos limpos, campos sujos e campos cerrados somam cerca de $78,5 \%$ de toda sua extensão [9].

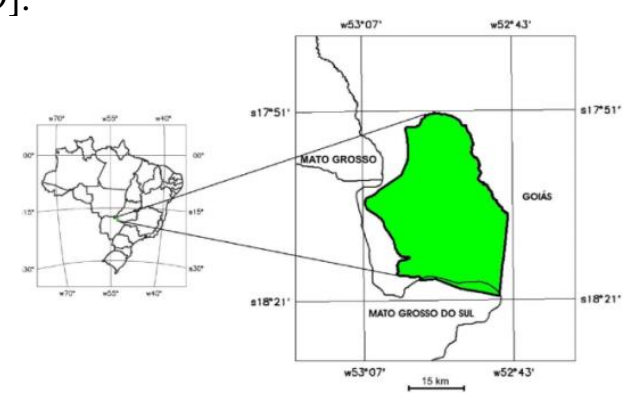

\footnotetext{
${ }^{2}$ A orientação de vertentes é definida como o ângulo azimutal correspondente à maior inclinação do terreno, no sentido descendente e é expressa em graus, de $0^{\circ}$ a $360^{\circ}$.
} 
Figura 1: (a) Localização do Parque Nacional das Emas.

Embora o fogo seja um evento endógeno e estruturante do Bioma Cerrado, com a presença de incêndios naturais durante o período chuvoso, nos dias de hoje, a pressão antrópica modifica este regime de fogo, com a presença de incêndios antropogênicos que são nocivos e devastadores [9]. Partindo do mapeamento do histórico de incêndios ocorridos no PNE ao longo dos últimos 40 anos, obtido a partir da interpretação de imagens de sensoriamento remoto orbital [5], foi possível compreender o comportamento do fogo no Parque, e identificar os seus principais fatores condicionantes. Analisando o histórico de incêndios mapeados e as informações geográficas disponíveis para o PNE [1], foi possível melhor compreender a dinâmica de propagação de incêndios e os fatores que nela influenciam, permitindo chegar às seguintes conclusões:

1. Ao longo de toda a extensão do PNE, os rios atuam como obstáculos naturais à propagação do fogo. Já a malha de aceiros, que compreendem faixas de descontinuidade traçadas na vegetação com o intuito de conter o avanço de incêndios a grandes áreas do Parque, quando está com a manutenção em dia, atua como obstáculo artificial, contendo a propagação do fogo.

2. Outro fator importante para a dinâmica de propagação é o acúmulo de combustível vegetal. Áreas queimadas recentemente não possuem vegetação seca suficiente acumulada na superfície para dar condições para o fogo se alastrar, e acabam atuando como barreiras à propagação. $\mathrm{O}$ efeito do tempo contado desde o último incêndio é mais intenso sobre as fisionomias abertas, sendo conduzido pelo comportamento fenológico da espécie predominante denominada capim-flecha (Tristachya leiostachya) [9]. O clímax de inflamabilidade é no período entre 3 e 4 anos sem queima, valor crítico de acúmulo de combustível, que cria condições para grandes e incontroláveis incêndios. As classes de vegetação definidas foram: FC1-CL1 (cerrado aberto com acúmulo baixo), que corresponde a áreas com menos de um ano sem queima; FC1-CL2 (cerrado aberto com acúmulo médio), que corresponde a áreas com mais de um e menos de três anos sem queima; FC1-CL3 (cerrado aberto com acúmulo alto), que corresponde a áreas com mais de 3 anos sem queima; FC2 (cerrado fechado); FC3 (campo úmido); e FC4 (floresta). A Figura 2(a) identifica estas classes sobre a região do PNE.

3. As classes de vegetação foram ordenadas em função da capacidade de manter o fogo, definida em termos de capacidade de ignição e de capacidade de propagação. A capacidade de ignição é a facilidade de a vegetação começar a queimar, dado que exista uma fonte de calor com energia suficiente. A capacidade de propagação é a facilidade do fogo se alastrar, dado que já tenha sido levado à ignição. Como os incêndios predominantes são de superfície, a abundância do combustível superficial é o critério para ordenação. Dentre os tipos fisionômicos presentes no PNE, a abundância de combustível vegetal é maior nas fisionomias abertas, uma vez que o estrato herbáceo/subarbustivo é mais denso e dominante [6]. Cada classe de combustível foi incluídaem um dos dois regime de suporte ao fogo: regime de propagação, onde o fogo encontra condições de auto sustentar; e regime de extinção, onde o fogo não encontra condições de se manter e se extingue. A escala comparativa das classes de vegetação é apresentada na Figura 2(b).

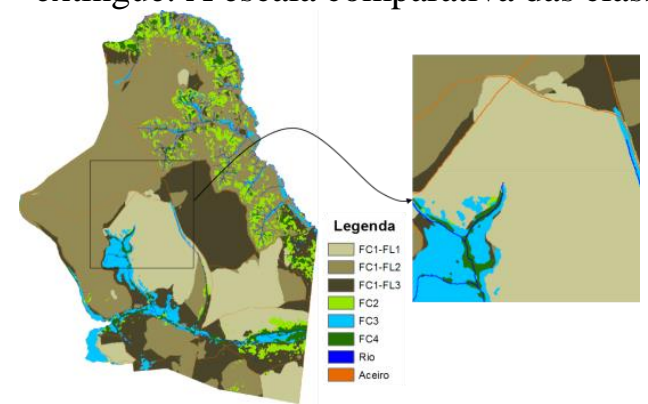

(a)

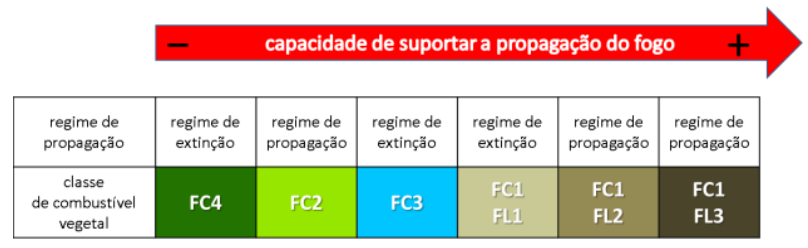

(b)

Figura 2: (a) Classes de vegetação e obstáculos à propagação. (b) Escala comparativa da capacidade de suportar a propagação do fogo.

\section{Metodologia}

O modelo utilizado neste trabalho é uma versão parametrizada do modelo baseado em autômatos celulares probabilísticos, que foi proposto e analisado em [2]. As parametrizações incluem: a definição 
da resolução espacial (tamanho da célula) e da resolução temporal (duração de uma iteração do modelo); a seleção de fatores condicionantes que influenciam na dinâmica de propagação do fogo; e a especificação da relação explícita entre os parâmetros do modelo e estas variáveis. O domínio espacial é representado por um conjunto de unidades discretas, chamadas células, estruturadas em um reticulado bidimensional quadrado denominado espaço celular. O tempo é contado por passos discretos ou iterações. Uma célula possui uma conectividade ou vizinhança com as oito células vizinhas do seu entorno. Cada célula possui um conjunto finito de estados. Somente células com cobertura vegetal podem ser levadas à ignição. Uma vez levada à ignição, a célula passa a ter o estado célula queimando $(\mathbf{F})$. Uma célula queimando pode mudar de estado para célula queimada $(\mathbf{O})$. Células que não possuem cobertura vegetal têm estado imutável, e são: células aceiro $(\mathbf{F B})$ e células rio $(\mathbf{R})$, e células queimadas $(\mathbf{O})$. A propagação do fogo ao longo do espaço celular é considerada como um evento estocástico, com uma probabilidade $S$ associada, denominada probabilidade efetiva de propagação do fogo, que depende de outras três probabilidades elementares, que são: a probabilidade $D$, que define arranjo da vegetação (densidade e continuidade) ao longo do espaço celular; a probabilidade $B$, que representa a dinâmica de combustão da célula e, define a probabilidade, avaliada a cada iteração, de uma célula que está queimando se tornar uma célula queimada; e a probabilidade $I$, que representa a dinâmica de ignição, e define a probabilidade, avaliada a cada iteração, do fogo avançar de uma célula vizinha que está queimando para a célula central. A Figura 3(a) mostra o diagrama de transição de estados das células do modelo, onde as células com vegetação compreendem as 6 classes de vegetação definidas na Sessão anterior.

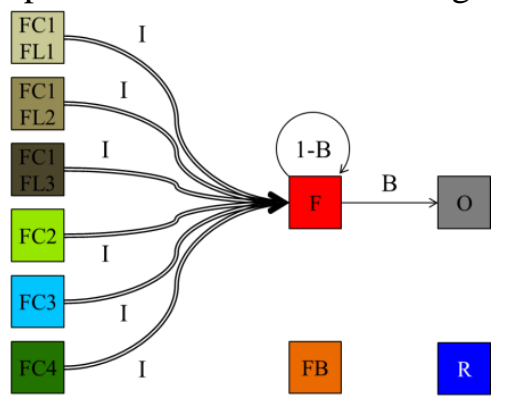

(a)

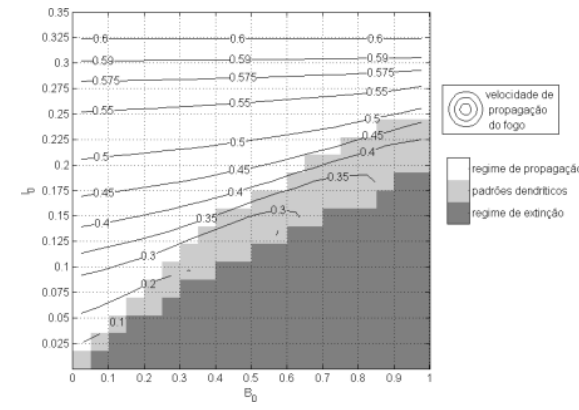

(b)

Figura 3: (a) Diagrama de transição de estados das células do modelo. (b) Valores de velocidade de propagação do fogo em função de $B$ e $I$, assumindo $D=1$.

Mediante o uso de simulações Monte-Carlo é possível estimar o valor da probabilidade $S[1,2]$. Dado que distribuição do estrato herbáceo/subarbustivo das classes de vegetação do PNE é contínua ao longo da superfície, assumimos o valor de $D=1$. A partir dos valores de $S$, foram definidas três classes de comportamento do fogo, que são: regime de propagação $(S=1)$, onde o fogo propaga-se livremente, com forma bem definida e sem chances de se extinguir; regime de extinção $(S=0)$, onde o fogo não propaga; e regime de padrões dendríticos $(0<S<1)$, onde o fogo propaga-se de maneira não-uniforme, sem forma definida e com chances do fogo se extinguir. Uma vez que a velocidade de propagação do fogo $R$ é proporcional a $S$, ao definirmos os valores das resoluções espacial $\Delta l=30$ metros e temporal $\Delta t=50$ segundos, podemos ter uma estimativa de todos os valores de velocidade de propagação do fogo ${ }^{3}$ para $S>0$, conforme exibido na Figura 3(b).

Os valores de $B$ e $I$ dependem dos fatores que condicionam a propagação do fogo. Os fatores condicionantes escolhidos são: a vegetação, representada em termos de classes de vegetação e respectivas classes de acúmulo, e teor de umidade do combustível; as condições atmosféricas, representada em termos da umidade relativa do ar, e velocidade e direção do vento; e a topografia, representada em termos de declividade e orientação de vertentes. Assim, assumimos que cada classe de vegetação possui valores elementares de probabilidades $B_{0}$ e $I_{0}$, que quantificam o potencial de cada classe em suportar a propagação do fogo, conforme escala apresentada na Figura 2(b). Os valores das probabilidades elementares são mostrados na Tabela 1, e foram definidos sobre as curvas de

\footnotetext{
${ }^{3}$ Por conta do domínio espacial ser discreto, os valores de resolução espacial de 30 metros e resolução temporal de 50 segundos, definem um valor máximo de velocidade de propagação do fogo igual a $R_{\max }=\Delta l / \Delta t=30 / 50=0,6 \mathrm{~m} / \mathrm{s}$, que correspondem ao fogo avançando uma célula por iteração, e condiz com a máxima velocidade de propagação do fogo documentada em experimentos de incêndios no Cerrado [4].
} 
velocidade do gráfico da Figura 3(b),tomando como base dados de velocidade de propagação do fogo registrados em incêndios experimentais [1].

\begin{tabular}{c|l|l|l|c|c|c}
\cline { 2 - 7 } & FC1-FL1 & FC1-FL2 & FC1-FL3 & FC2 & FC3 & FC4 \\
\hline$B_{0}$ & 0,350 & 0,250 & 0,220 & 0,450 & 0,700 & 0,800 \\
\hline$I_{0}$ & 0,075 & 0,115 & 0,152 & 0,100 & 0,115 & 0,075 \\
\hline
\end{tabular}

Tabela 1: Valores das probabilidades elementares para cada classe de vegetação.

As parametrizações incluem os efeitos das características da vegetação, das condições atmosféricas e da topografia, e permitem que a dinâmica do modelo varie tanto no espaço como no tempo em função destes fatores. As relações apresentadas foram extraídas de modelos empíricos da literatura de modelagem de incêndios de vegetação [1], e permitem relacionar as probabilidades $B$ e $I$ com estes fatores. A Tabela 2 resume as parametrizações do modelo.

Probabilidade de ignição: Probabilidade de extinção:

$$
I=I_{0} \cdot \lambda_{M} \cdot \lambda_{S} \cdot \lambda_{W} \quad B=B_{0} \cdot\left(1 / \lambda_{M}\right)^{b_{1}}
$$

Fator que introduz os efeitos da umidade da umidade da vegetação: $\lambda_{M}=\exp \left(-b_{2} \cdot M\right)$

- $\quad M$ : teor de umidade da vegetação, expressa em porcentagem, variando de $0 \%$ a $100 \%$.

- $0 \leq b_{1}, b_{2} \leq 1$ : constante 2 empírica que ajusta o efeito da umidade da vegetação.

Fator que introduz os efeitos da topografia: $\lambda_{S}=\exp \left(a \cdot \theta_{S}\right)$

- $\theta_{S}$ : é o valor da declividade do caminho percorrido pelo fogo, em graus.

- $0 \leq a \leq 1$ : constantes empíricas que ajustam o efeito da inclinação da superfície.

Fator que introduz os efeitos da velocidade e direção do vento: $\lambda_{W}=1+c_{1} \cdot f(\omega) \cdot U^{c_{2}}$

- $U$ : velocidade do vento $(\mathrm{m} / \mathrm{s})$

- $\omega$ : direção do vento

- $f(\omega)=\exp \left(c_{3} \cdot U \cdot(\cos (\omega)-1)\right)$ : função que representa o efeito da direção do vento $\omega$ sobre a direção de propagação.

- $0 \leq c_{1}, c_{2}, c_{3} \leq 1$ : constantes empíricas que ajustam o efeito da velocidade e direção do vento.

Tabela 2: Resumo das parametrizações do modelo.

\section{Resultados}

O ajuste e aplicação do modelo foi realizado utilizando dados de um incêndio documentado ocorrido no dia 28 de julho de 2007, com início às 15:00 $\mathrm{H}$ e término em torno das 5:00 $\mathrm{H}$ do dia seguinte (duração de 15 horas). A Figura 3 mostra uma imagem de sensoriamento remoto que registra a cicatriz do incêndio e as condições atmosféricas durante o evento. A causa do incêndio foi acidental, durante a manutenção de um aceiro, e o foco ocorreu conforme indicado na imagem. Devido a ausência de manutenção, os demais aceiros não foram eficazes para conter o avanço da frente de fogo, como podemos observar na Figura 3.

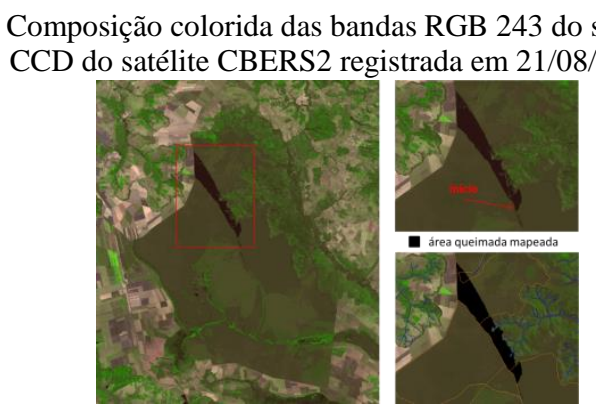

\begin{tabular}{cccc}
\hline $\begin{array}{r}\text { Condições atmosféricas registradas por uma estação meteorológica situada } \\
\text { a cerca de 30 Km do PNE, em Chapadão do Céu/GO. }\end{array}$ \\
\hline Data e Hora & $\begin{array}{c}\text { Umidade } \\
\text { Relativa } \\
(\%)\end{array}$ & $\begin{array}{c}\text { Velocidade do } \\
\text { Vento (m/s) }\end{array}$ & $\begin{array}{c}\text { Direção do } \\
\text { vento } \\
\text { (graus) }\end{array}$ \\
\hline $\begin{array}{c}\text { 28/07/2007 12:00 } \\
\text { 28/07/2007 18:00 }\end{array}$ & 58 & 2,9 & 350 \\
\hline $\begin{array}{l}28 / 07 / 2007 \\
29 / 07 / 200700: 00\end{array}$ & 55 & 4,0 & 340 \\
\hline $\begin{array}{l}\text { 29/07/2007 00:00 } \\
\text { 29/07/2007 06:00 }\end{array}$ & 71 & 2,9 & 320 \\
\hline
\end{tabular}

Figura 3: Informações do incêndio utilizado para o ajuste do modelo.

A etapa de ajuste consiste em encontrar os valores ideais das constantes empíricas $a, b_{1}, b_{2}, c_{1}$, $c_{2}$ e $c_{3}$ para que o incêndio simulado reproduza de maneira mais próxima possível o incêndio real. Este procedimento de ajuste ótimo é realizado via meta-heurística, onde é utilizado o algoritmo de vaga-lumes [10]. Foi realizado um total de 50 execuções independentes, utilizando 32 vaga-lumes, que 
se movimentam ao longo do espaço de busca durante 30 iterações do algoritmo. A função de avaliação da solução candidata compara o incêndio simulado em relação ao dado real, em termos de área queimada e tempo de duração [1]. Cada avaliação da função candidata é obtida por uma média de 50 simulações independentes do modelo. Os valores das constantes empíricas, incluindo média e desvio padrão, obtidos são mostrados na Tabela 3. A Figura 4 compara o incêndio real com o incêndio simulado, utilizando os valores de parâmetros obtidos no ajuste. $\mathrm{O}$ nível de discordância entre as áreas é de $30 \%$ e o incêndio simulado durou cerca de 14 horas.

\begin{tabular}{cc}
\hline Constante empírica & Valor estimado \\
\hline$a$ & $0,0645 \pm 0,0103$ \\
\hline$b_{1}$ & $0,3140 \pm 0,0094$ \\
\hline$b_{2}$ & $0,0061 \pm 0,0015$ \\
\hline$c_{1}$ & $0,1852 \pm 0,0191$ \\
\hline$c_{2}$ & $1,0159 \pm 0,0881$ \\
\hline$c_{3}$ & $0,2102 \pm 0,0271$ \\
\hline
\end{tabular}

Tabela 3: Valores obtidos para as constantes empíricas após a etapa de ajuste do modelo.
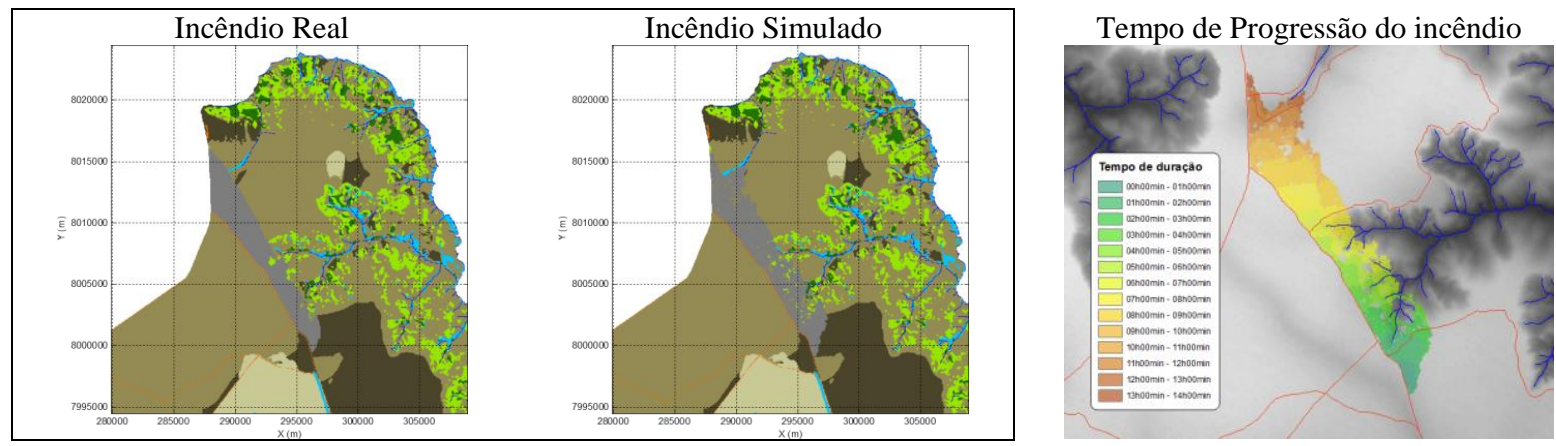

Figura 4: Comparação incêndio real x incêndio simulado e tempo de progressão do incêndio simulado.

Com o intuito de testar o ajuste do modelo, duas análises são realizadas. Na primeira, os valores das constantes empíricas são fixados e os valores das probabilidades elementares são modificados em $\pm 1 \%$. A Figura 5 mostra o resultado das simulações utilizando os distintos valores de $B_{0}$ e $I_{0}$. Nas simulações realizadas, somente para $I_{0}-1 \%$ e $B_{0}-1 \%$ (Figura 5(b)), e $I_{0}-1 \%$ e $B_{0}+1 \%$ (Figura $5(\mathrm{~d})$ ), o incêndio se extinguiu antes do tempo de duração, durando, respectivamente, $13 \mathrm{~h} 48 \mathrm{~min}$ e 12h18min. Conforme observado na Figura 5(a) e na Figura 5(c), o aumento nos valores de $I_{0}$ resultou em incêndios de maiores proporções. Já a diminuição, resultou em incêndios de menores proporções. $\mathrm{Na}$ segunda análise, os valores de $I_{0}$ e $B_{0}$ são fixados e um total de 1000 simulações foi realizado utilizando valores aleatórios das constantes empíricas, sorteados de acordo com os valores da média e desvio padrão apresentados na Tabela 3 . A proporção de vezes a célula queimou foi computado e o resultado é mostrado na Figura 5(e). Analisando a Figura 5(e), pode-se perceber que os valores de elevada frequência seguem a forma básica da área queimada simulada, indicando uma boa resposta às variações dos valores das constantes empíricas em torno dos valores obtidos no ajuste.

\section{Considerações finais}

Uma importante contribuição científica desta pesquisa está na idealização, ajuste e aplicação de um modelo matemático para simular incêndios de vegetação no contexto do bioma Cerrado. A abordagem utilizada e a metodologia de ajuste mostraram-se promissoras, sendo baseada em duas etapas. Na primeira, os valores das probabilidades elementares para cada tipo de vegetação, e respectivas classes de acúmulo, são determinados com base em medidas experimentais e conhecimento especialista. Na segunda etapa, valores ideais para as constantes empíricas que ajustam as relações explícitas entre os parâmetros do modelo e os fatores condicionantes são obtidas via método de otimização. Uma proposta de continuidade desta pesquisa é a aplicação e a especialização deste modelo para uma gama maior de situações reais e outras Unidades de Conservação, visando 
operacionalizá-lo como uma ferramenta para auxílio a ações que envolvam a tomada de decisão no combate e na prevenção de incêndios de vegetação.

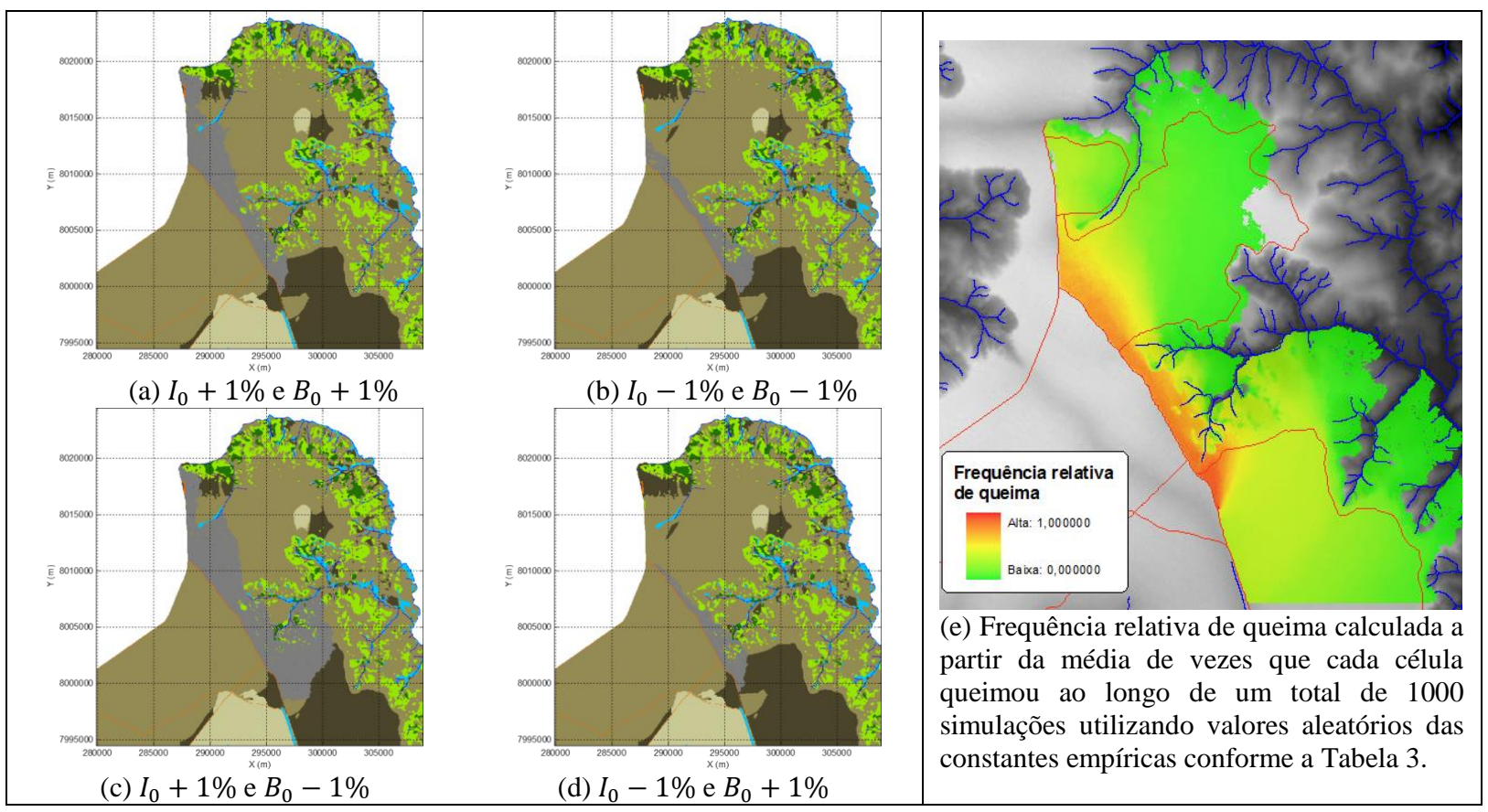

Figura 5: Em (a) a (d) são apresentados resultados de simulações utilizando distintos pares de valores $B$ e $I$, definidos em torno de $\pm 1 \%$ do valor escolhido empiricamente. Em (e), a análise de estabilidade do ajuste é apresentada por meio da frequência relativa de queima obtida por várias simulações utilizando valores aleatórios de constantes empíricas geradas em torno dos valores obtidos no ajuste.

\section{Referências}

[1] Almeida, R. M. Modelagem da propagação do fogo como ferramenta de auxílio à tomada de decisão no combate e prevenção de incêndios no Parque Nacional das Emas, GO. 2012. 121 f. Tese (Doutorado em Computação Aplicada) - Instituto Nacional de Pesquisas Espaciais, São José dos Campos. 2012.

[2] Almeida, R. M.; Macau, E. E. N. Stochastic cellular automata model for wildland fire spread dynamics. Journal of Physics: Conference Series Volume, v. 285, n. 1, 2011.

[3] Finney, M.; Grenfell, I.; Mchugh, C.; Seli, R.; Trethewey, D.; Stratton, R.; Brittain, S. A method for ensemble wildland fire simulation. Environmental Modeling and Assessment, v. 16, p. 153-167, 2011.

[4] Finney, M. A.; Cohen, J. D.; Mcallister, S. S.; Jolly, W. M. On the need for a theory of wildland fire spread. International Journal of Wildland Fire, v. 22, n. 1, p. 25-36, 2013.

[5] França, H.; Ramos Neto, M. B.; Setzer, A. O fogo no Parque Nacional das Emas. Brasília, DF: Ministério do Meio Ambiente, 2007. (Série Biodiversidade, v. 27).

[6] Ottmar, R.; Vihnanek, R. E.; Miranda, H. S.; Sato, M. N.; Andrade,S. M. Stereo Photo Series for Quantifying Cerrado Fuels in Central Brazil - Volume I. Portland, OR: Pacific Northwest Research Station, Forest Service, U.S. Department of Agriculture, 2001. (General technical report PNW-GTR519).

[7] Pastor, E.; Zarate, L.; Planas, E.; Arnaldos, J. Mathematical models and calculation systems for the study of wildland fire behaviour. Progress in Energy and Combustion Science, v. 29, n. 2, p. 139-153, 2003.

[8] Pyne, J. S.; Andrews, P. L.; Laven, R. D. Introduction to wildland fire. 2. ed. New York, NY: John Wiley\& Sons, 1996.

[9] Ramos Neto, M. B. O Parque Nacional das Emas (GO) e o fogo: Implicações para a conservação biológica. Tese (Doutorado) - Instituto de Biociências, Universidade de São Paulo, São Paulo, SP, 2000.

[10] Yang, X. S. Nature-Inspired Metaheuristic Algorithms. Frome, UK: Luniver Press, 2008. 